OBITUARY

\title{
In Memoriam Sören Stenlund (1943-2019)
}

Sören Stenlund began his academic career with work in philosophical logic and the philosophy of mathematics, culminating with his doctoral dissertation in Theoretical Philosophy, Combinators, $\lambda$-terms and Proof Theory (Dordrecht: Reidel, 1972), which was considered a landmark in the field. After defending, he was employed as Docent at the Department of Philosophy in Uppsala, where he pursued his researches in the philosophy of language, logic and mathematics and was promoted to Senior Lecturer in 1980. It was during this period that Stenlund began searching for answers to fundamental questions regarding the assumptions built into the techniques and conceptual apparatus of academic philosophy, and found inspiration in the work of Ludwig Wittgenstein. In 1980, he published Det osägbara (Stockholm: Norstedts), a personal and impassioned polemic against the conventional wisdom of professional philosophy at the time, that was to mark a turning point in his thought. The controversy over the book in Sweden could be compared to the reaction to Richard Rorty's Philosophy and the Mirror of Nature, which came out in the US around the same time. In both cases, the books were regarded as vitriolic caricatures by some, as pioneering and powerful philosophical critiques, by others. In the case of Stenlund, the book received national public attention uncommon for works in philosophy, and was lauded as a milestone (Expressen 30/12 1980) by one of Sweden's most acclaimed novelists and essayists, Lars Gustafsson, who also had a $\mathrm{PhD}$ in philosophy.

The most important conceptual points of Det osägbarawere ultimately to have repercussions not only for Stenlund's own work, 
but for a generation of students and colleagues in numerous disciplines in Sweden, as well as for Wittgenstein-inspired philosophy worldwide. The strong international standing of the Nordic countries in the new orientation of Wittgensteinian philosophy today is heavily indebted to Stenlund. One of the main themes of the book was how contemporary ideals and assumptions about the point and purpose of philosophy as a kind of science of necessary truths that takes the whole of language, the mind or the world as its object of study, distorts the knowledge that it takes itself to categorize and systematize. The consequence of this insight for Stenlund was that he found himself compelled to find answers to the kinds of questions that concerned him not only, or even primarily, in journals and books in contemporary professional philosophy, but also in works in history, linguistics, anthropology, literature, theology and psychology. In later publications, such as Language and Philosophical Problems (London: Routledge, 1991), Stenlund developed a number of the themes from Det osägbara in relation to problems in the philosophy of mind, connecting the latter to issues about meaning and mathematics arising out of certain preconceptions about the nature of language and the technical terminology, classifications and formal methods associated with these. Here again, he was concerned to show that the conceptual apparatus that we utilize in intellectualizing about a subject matter, be it language, artificial intelligence or mathematics, tends to leave the actual substance of the problems behind. Stenlund saw this tendency as a common source of confusion arising out of received ways of treating different kinds of problems as if the apparatus itself were a given (a specialization). His work showed how the solution to the problems was often to be found by examining their roots.

During the 1980's, long before interdisciplinarity was a catchword, Stenlund's higher seminar in theoretical philosophy began attracting graduate students and scholars in other disciplines, with a focus on solving shared conceptual problems. One of Stenlund's great contributions to the intellectual atmosphere in Uppsala was showing how certain problems arising in philosophy were directly germane to the interpretation of literature, the study of intellectual history, linguistic theories, sociological ideas, debates in 
mathematics, and issues in theology. But it was always the problems, rather than disciplines, doctrines or debates that were central to the discussions. Stenlund's gentle demeanour and humility, combined with his breadth of interests, depth of reflection and acuity of thought, made him something of a paragon for what many thought a philosopher should be, although he very much disliked being the focus of admiring attention. The openness of the lively and engaged environment he created also had the effect of attracting women to a discipline that was at the time, and still is, although to a lesser degree, dominated by men and a masculinist culture. He was always receptive to new ideas and alternative approaches, and lent his enthusiastic support to initiatives that were not necessarily congenial to his own interests or philosophical ideals and inclinations. He was curious about other traditions and styles of thinking, and had no trouble finding common ground with scholars working within areas very different from his own, as long as they were serious about the problems they were addressing. These engagements with other disciplines and orientations in philosophy stimulated him to write essays and articles far afield from his original areas of specialization, many of these, unfortunately, only available in Swedish. In 2000, the year he was appointed Professor of Theoretical Philosophy, he anthologized a number of his most important contributions to the philosophy of culture in the volume Filosofiska uppsatser (Skellefteå: Artos \& Norma bokförlag).

In the 1990's, he had devoted himself largely to advising, supporting and supervising graduate students, both his own and others, many of whom are today docents and professors working in a variety of domains, including gender theory, bioethics, philosophical anthropology, cultural theory, philosophy of film, literary studies and psychology, as well as phenomenology and existentialism, epistemology, ordinary language philosophy, the philosophy of mathematics and the theory of science. Upon his retirement, Stenlund could be seen carrying loads of books that he had borrowed from the library on the philosophy of mathematics, in preparation for what would be two of his very last publications: The Origin of Symbolic Mathematics and the End of the Science of Quantity (Uppsala Philosophical Studies, 2014) and "The Origin of Symbolic 
Mathematics and Its Significance for Wittgenstein's Thought" (Nordic Wittgenstein Review, Vol. 4, Nr. 1, 2015). When asked about taking on such a project when he was finally free from academic responsibilities and could do as he liked, he remarked: "This is my chance to return to my first love."

Sharon Rider

Professor of Logic and Metaphysics at Uppsala University Deputy Director, The Engaging Vulnerability Program sharon.rider@filosofi.uu.se engagingvulnerability.se

We are thankful to Professor Rider for the permission to publish this very slightly revised version of an obituary originally written for the Department of Philosophy at Uppsala University, available at: https://www.filosofi.uu.se/nyheter/?tarContentId=806304. 